\title{
No dejemos morir al hueso: interiorizándonos con los procesos óseos avasculares
}

\section{Do not let the Bone Die: Interiorizing with the avascular Bone Processes}

\author{
Karen Mena ${ }^{1}$ Margareth Mendoza ${ }^{1}$ Juan Manuel Galván ${ }^{1} \quad$ Esteban Jeanmaire $^{1}$ Luciana Ferrari $^{1}$ \\ Ricardo Cobeñas ${ }^{1}$ \\ 1 Departamento de Imágenes, Centro de Educación Médica e
Investigaciones Clínicas, Hospital Universitario Sede Saavedra,
Ciudad Autónoma de Buenos Aires, Argentina \\ Address for correspondence Karen Mena, MD, Av. Monroe, 2448 \\ Ciudad Autónoma de Buenos Aires, Argentina (e-mail: \\ karen_mena90@hotmail.com).
}

Rev Argent Radiol 2020;84:93-106.

\section{Resumen \\ Palabras clave \\ - osteonecrosis \\ - enfermedad ósea \\ - necrosis de cabeza femoral}

\section{Abstract \\ Keywords \\ - osteonecrosis \\ - bone disease \\ - femur head necrosis}

El objetivo de este artículo es realizar una revisión de las localizaciones, causas y hallazgos radiológicos específicos de los procesos avasculares óseos.

Se define como isquemia ósea a las alteraciones ocasionadas por déficit de irrigación, llevando a la destrucción del hueso. Existen diferencias entre necrosis isquémica e infarto óseo, en base al sitio óseo de afectación. La etiología traumática es la más frecuente y suele ser unilateral. Los sitios de presentación más frecuentes son: cabeza femoral y humeral, rodilla y semilunar.

La resonancia magnética (RM) es considerada la modalidad de imagen más sensible y específica, tanto para el diagnóstico temprano como estadificación y control.

El conocimiento de las causas, características radiológicas y sus diferentes fases evitan el diagnóstico erróneo de otras etiologías, como las primarias o infecciosas, facilitando un correcto algoritmo terapéutico.

The aim of this article is to review the locations, causes and specific radiological findings of avascular bone processes.

Bone ischemia is defined as the alterations caused by irrigation deficit, leading into the bone destruction. However, there are differences between ischemic necrosis and bone infarction, based on the bone site of involvement.

The most frequent etiology is traumatic and is usually unilateral. The most frequent sites of presentation are: femoral and humeral head, knee, and lunate.

Magnetic resonance imaging (MRI) is considered the most sensitive and specific imaging modality for early diagnosis, staging and control.

The knowledge of the causes, radiological findings and their different phases avoid the erroneous diagnosis of other lesions, such as primary or infectious, facilitating a correct therapeutic algorithm. received

November 18, 2019

accepted

August 4, 2020
DOI https://doi.org/

10.1055/s-0040-1716383.

ISSN 1852-9992.
Copyright (c) 2020, Sociedad Argentina de Radiología. Publicado por Thieme Revinter Publicações Ltda., Rio de Janeiro, Brazil. Todos los derechos reservados.
License terms

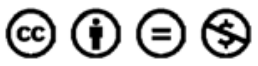




\section{Introducción}

El hueso, como órgano vivo, requiere un suministro de sangre para desarrollar su remodelación y actividad. Cuando es desprovisto de circulación, sufre una isquemia secundaria que produce la lesión o muerte del tejido. Sus consecuencias dependerán del hueso y la localización comprometida. Los hallazgos serán característicos según se produzcan a nivel diafisario, epifisario o metafisario, así como también si sucede en un hueso adulto o en crecimiento.

Se ha estimado que existen alrededor de entre $20.000 \mathrm{y}$ 30.000 nuevos casos de isquemia al año en Estados Unidos, y que constituye el 10\% de las causas de reemplazos de cadera que se realizan en ese país. La relación varones:mujeres varía según las comorbilidades asociadas. ${ }^{1}$

En el presente trabajo realizaremos una revisión de tema de los diferentes sitios de localización de procesos avasculares óseos mediante la compilación de casos por resonancia magnética (RM) que se presentaron en nuestra institución. Desarrollaremos los conceptos básicos e identificaremos el espectro de hallazgos radiológicos específicos en cada topografía y sus posibles causas con el fin de realizar una detección temprana.

\section{Definición de necrosis ósea avascular e infarto óseo}

Aunque necrosis ósea avascular (NOA) e infarto óseo son términos equivalentes y que se traducen como muerte ósea, es importante destacar su diferencia, debiéndose a su localización. La osteonecrosis (ON) es la afectación epifisaria o subarticular que involucra a la cortical, y el infarto óseo se reserva para las localizaciones metafisarias y diafisarias en las que la necrosis afecta únicamente al hueso medular. ${ }^{2}$

La ON, también conocida como necrosis ósea avascular (NOA) o aséptica, es una entidad clínica caracterizada por necrosis del hueso trabecular y de médula ósea producida por una disrupción en el flujo sanguíneo temporal o permanente, favoreciendo la muerte isquémica de los constituyentes celulares, generando la destrucción del hueso o de la superficie de las articulaciones. ${ }^{3,4}$

El infarto, como en cualquier otro órgano, constituye un área localizada de necrosis que se produce por una disminución significativa del aporte arterial o del drenaje venoso, afectando las regiones donde predomina la médula ósea grasa, ya que se encuentra pobremente vascularizada. ${ }^{4}$

\section{Fisiopatología}

Las múltiples etiologías relacionadas con la NOA se caracterizan por causar una alteración en la vascularización del hueso subcondral que lleva a la isquemia del tejido, lo cual termina produciendo muerte de los osteocitos y colapso de la superficie articular, pudiendo desarrollarse por uno de los siguientes mecanismos: interrupción de la irrigación arterial, obstrucción del drenaje venoso o daño de la pared de los vasos. $^{4}$

La muerte celular no es inmediata, se produce a través de varias etapas progresivas de la lesión isquémica. La aparición de la lesión y la rapidez con que se produce la muerte celular dependerá de la sensibilidad de cada tipo de célula, del grado y el tiempo de duración de la anoxia..,5

En el infarto óseo se produce aumento de la presión intraósea por edema en médula ósea, induciendo un aumento de osteoclastos, los cuales reabsorben el hueso trabecular subcondral. Estas trabéculas alteradas y disminuidas ante reiterada carga articular terminan colapsando.

\section{Causas de osteonecrosis}

La ON se puede clasificar en dos grandes grupos según su etiología: primaria o idiopática y secundaria. Dentro de esta última, la subclasificación es variada y son muchos los procesos que se han asociado a su desarrollo (-Tabla $\mathbf{1}$ ). Las causas más comunes son traumatismo, corticosteroides y alcoholismo. La ON traumática es unilateral, en contraposición a la no traumática, que es bilateral. ${ }^{6}$

La patogenia por corticosteroides es controvertida, relacionándose con alteraciones en el metabolismo de las grasas según dos teorías apoyadas:

1. Cambios locales del hueso por el aumento de los adipocitos intraóseos y la presión intraósea con resultado de isquemia;

2. Causa embólica, debido a la producción lipídica aumentada.

La probabilidad de ON aumenta con una dosis más alta de esteroides ( $>20 \mathrm{mg} /$ day, $>10 \mathrm{mg} /$ day) y una duración más prolongada de la terapia. ${ }^{3,6}$ Las mismas teorías son aceptadas para explicar el riesgo aumentado por el consumo excesivo de alcohol.

Tabla 1 Causas de ON secundaria

\begin{tabular}{|l|}
\hline CAUSAS DE OSTEONECROSIS SECUNDARIA \\
\hline Traumatismo (fractura o luxación) \\
\hline Hemoglobinopatías (anemia falciforme) \\
\hline $\begin{array}{l}\text { Hipercolesterolismo exógeno o endógeno (tratamiento con } \\
\text { corticoides, enfermedad de Cushing) }\end{array}$ \\
\hline Trasplante renal \\
\hline Alcoholismo \\
\hline Pancreatitis \\
\hline Disbarismo (enfermedad de Caisson) \\
\hline Enfermedad de pequeños vasos (colagenopatías) \\
\hline Enfermedad de Gaucher \\
\hline Gota e hiperuricemia \\
\hline Irradiación \\
\hline Sinovitis con elevación de la presión intraarticular. \\
\hline
\end{tabular}


La dosis acumulada de corticoesteroides en pacientes con trasplante renal o de médula ósea son factores de riesgo relacionados con el desarrollo de $\mathrm{ON}$.

La enfermedad de células falciformes, la trombofilia y la hipofibrinólisis son causas de ON por trombosis venosa o incluso arterial. . $^{3,6}$

Se debe mencionar la ON maxilar, relacionada al uso de bifosfonatos, con el tratamiento odontológico invasivo como factor de riesgo para su desarrollo. ${ }^{7}$

\section{Osteonecrosis de cadera/cabeza femoral}

La cabeza femoral es la zona más frecuente de ON, ocurre en el 15\% al 80\% de los pacientes con fractura de cuello femoral, así como en pacientes con tratamiento corticoideo. ${ }^{8}$ La ON de cadera suele ser bilateral y el riesgo de la bilateralidad es mayor dentro de los dos años posteriores al diagnóstico unilateral. ${ }^{9}$

La ON atraumática de cadera con frecuencia es asintomática, siendo difícil establecer el inicio del proceso. Al presentarse con sintomatología, esta se caracteriza por dolor en la articulación de la cadera, pudiendo irradiarse hacia la ingle, región anterior del muslo o hasta la rodilla.8

La RM es el método más sensible y específico para detectar los hallazgos iniciales por imágenes de la ON. Existen, además, características por RM que nos permiten determinar los factores que aumentan el riesgo para el desarrollo de la ON. Entre ellos se encuentran la cicatriz fiseal gruesa y la conversión temprana a médula amarilla. ${ }^{6}$

El patrón más común de la ON es la médula amarilla en la epífisis rodeada de una línea de morfología en anillo o en cuña, de baja señal en todas las secuencias en relación a la formación de tejido esclerótico (-Fig. 1). Además, en estos casos se puede observar el signo de doble línea, en relación a otro anillo profundo hiperintenso en secuencias ponderadas en T2, correspondiente a tejido de granulación en remodelación. ${ }^{6,10}$

Existen varias escalas para determinar el grado de severidad de la $\mathrm{ON}$ de cadera mediante hallazgos imagenológicos con el fin de identificar y guiar el tratamiento adecuado, siendo las clasificaciones de Fitcat y Arlet, y/o Steinberg ( - Tablas 2 y $\mathbf{3}$ ) las más utilizadas por los
Tabla 2 Sistema de estadificación Fitcat y Arlet para la necrosis avascular de la cadera

\begin{tabular}{|l|l|l|}
\hline ESTADIO & CLÍNICA & HALLAZGOS RADIOLÓGICOS \\
\hline I & Sin dolor & $\begin{array}{l}\text { RX normal } \\
\text { Disminución o aumento de la } \\
\text { captación en la gammagrafía ósea }\end{array}$ \\
\hline II & + - dolor & $\begin{array}{l}\text { Cambio variable en la apariencia } \\
\text { del hueso trabecular con esclerosis } \\
\text { y formación de quistes con forma } \\
\text { de la cabeza femoral conservada }\end{array}$ \\
\hline III & Dolor & $\begin{array}{l}\text { Colapso del hueso subcondral/ } \\
\text { signo de media luna secundaria a } \\
\text { fractura del hueso subcondral }\end{array}$ \\
\hline IV & Dolor & $\begin{array}{l}\text { Marcado colapso del hueso sub- } \\
\text { condral con preservación del } \\
\text { espacio articular }\end{array}$ \\
\hline V & Dolor & Artrosis secundaria \\
\hline
\end{tabular}

Tabla 3 Sistema de estadificación de Steinberg para ON

\begin{tabular}{|l|l|}
\hline ESTADIO & HALLAZGOS EN IMÁGENES \\
\hline $\mathbf{0}$ & Hallazgos normales radiológicos, TC y RM \\
\hline I & RX normal; TC y RM alteradas \\
\hline II & $\begin{array}{l}\text { RX alterada con cambios quísticos y } \\
\text { escleróticos en cabeza femoral }\end{array}$ \\
\hline III & $\begin{array}{l}\text { Colapso subcondral produciendo signo } \\
\text { de la semiluna }\end{array}$ \\
\hline IV & Aplastamiento de la cabeza femoral \\
\hline V & $\begin{array}{l}\text { Espacio articular estrechado con o sin } \\
\text { afectación acetabular }\end{array}$ \\
\hline VI & $\begin{array}{l}\text { Cambios secundarios de degeneración } \\
\text { avanzada }\end{array}$ \\
\hline
\end{tabular}

La extensión o grado de afectación debe ser indicado como $\mathrm{A}=$ leve, $\mathrm{B}=$ moderada, $\mathrm{C}=$ severa.

radiólogos al evaluar la progresión, desde la enfermedad radiológicamente negativa hasta el colapso de la cabeza femoral con desarrollo secundario de osteoartritis (-Figs. 2 y 3). ${ }^{6}$ Es de conocimiento que la importancia clínica de la ON depende casi por completo de la probabilidad de colapso
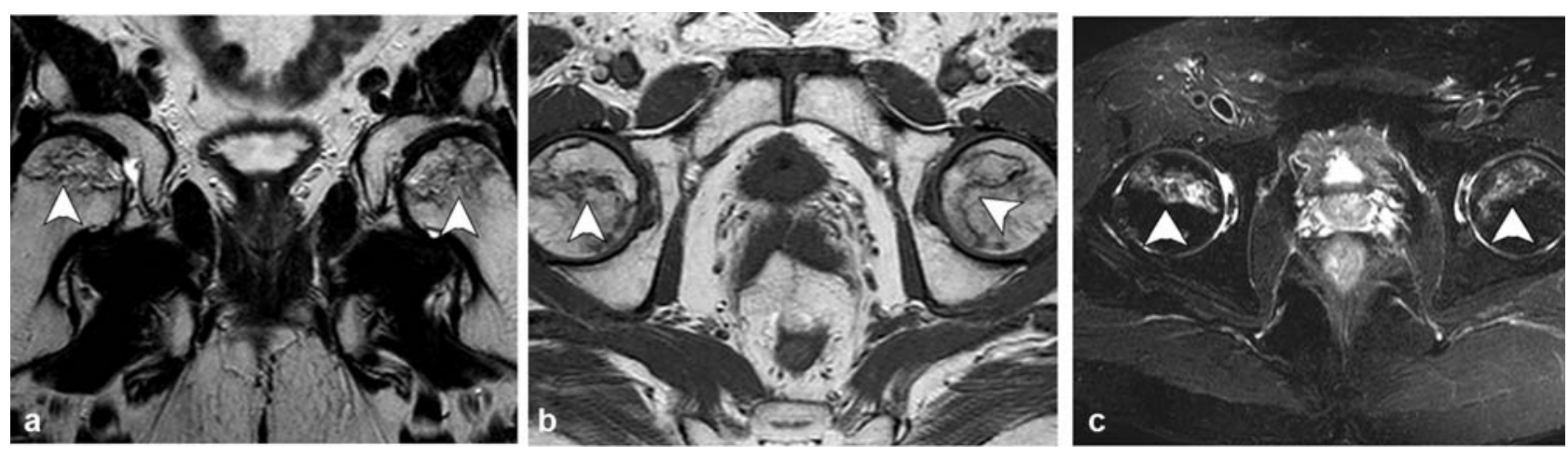

Fig. 1 Paciente de sexo masculino de 53 años en una RM por fístula anal. Se realizó el hallazgo de ON de cadera bilateral: a nivel subcortical, en las vertientes superiores de ambas cabezas femorales, se observan lesiones de señal grasa con bordes geográficos de baja señal ponderada en T2 y T1 (cabezas de flecha a y b) y de alta señal en STIR (c). 

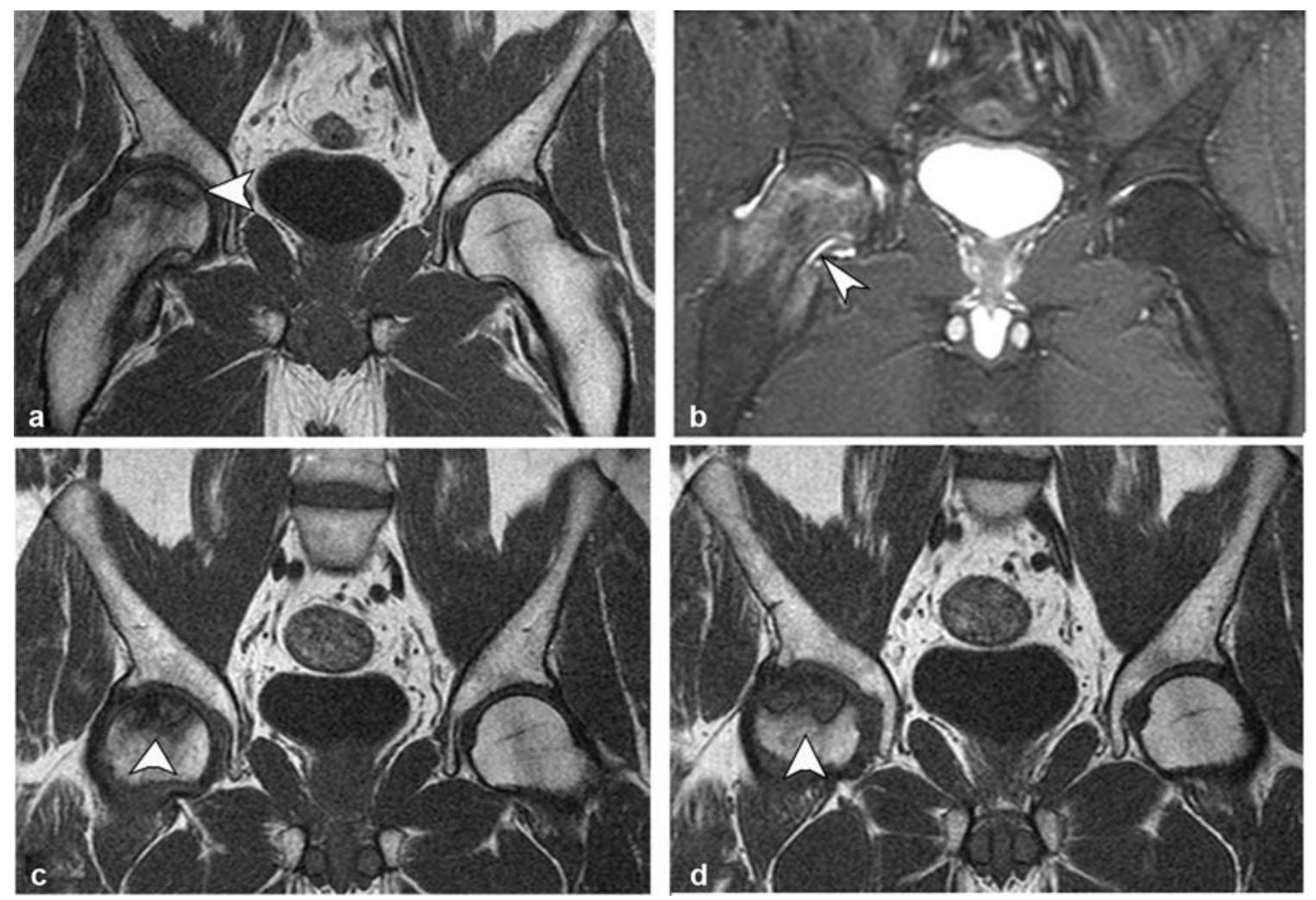

Fig. 2 Paciente de 47 años con ON de epífisis femoral. Se observa irregularidad de la cortical a nivel del borde anterior y superior de la cabeza femoral derecha en asociación con imagen subcondral de alta señal ponderada en T1 (cabeza de flecha en a) y baja señal en STIR, asociado a edema óseo en cuello (punta de flecha en b). En el transcurso de 6 meses, se observa progresión de la hipointensidad ponderada en T1, asociada a leve colapso cortical (cabeza de flecha en c y d).
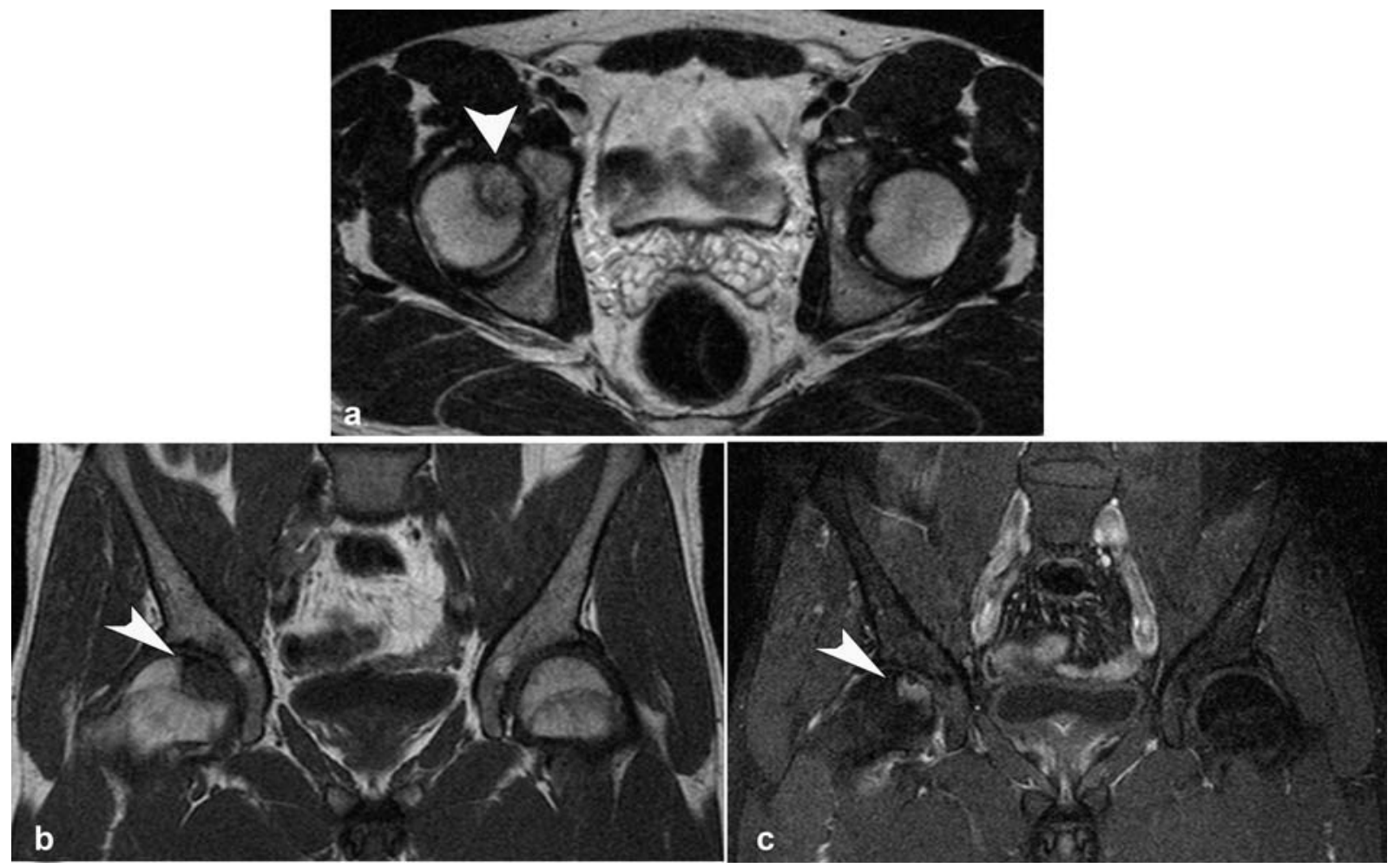

Fig. 3 Paciente de 32 años con ON de epífisis femoral: lesión cortico-subcortical a nivel de la epífisis femoral derecha (cabezas de flecha), de alta señal ponderada en T2 (a) y baja señal en T1 (b), con borde geográfico hipointenso en ambas secuencias, mostrando realce homogéneo central tras la administración del contraste endovenoso (cabeza de flecha en c). Se observa además engrosamiento y realce de la cápsula articular coxofemoral derecha y discreto aumento del líquido articular (c). 
articular, por lo que el volumen de la cabeza femoral afectada sería su predictor más relevante.

El tratamiento de la ON en estadios tempranos, tanto I y II de las clasificaciones antes mencionadas, apunta a evitar la degeneración articular. Para esto se acude al tratamiento conservador con bifosfonatos, incluyendo oxigenoterapia hiperbárica y medidas de descarga, ${ }^{9}$ en ocasiones la descompresión o resección focal, siendo este último utilizado incluso en estadio III complementándose con injertos óseos, debido a que el pronóstico es mejor cuando se aplican en estadios más precoces. ${ }^{11}$ La enoxaparina puede prevenir la progresión de la $\mathrm{ON}$ con etiología de trombofilia o trastornos hipofibrinolíticos. ${ }^{10}$ En los estadios avanzados, de III en adelante, el tratamiento de elección es la artroplastia total de cadera, especialmente en edades avanzadas, obteniéndose un buen resultado. Si existieran contraindicaciones o se optara por diferir el uso de prótesis, como es en el caso de pacientes jóvenes, se realizan osteotomías.

Los factores de mal pronóstico que determinan el probable colapso articular son: estadio avanzado al momento del diagnóstico, extensión o volumen de la cabeza femoral involucrada (>50\% de la cabeza femoral), su localización (zona anterolateral), y aumento del grosor de la zona de reparación. Otros factores a tener en cuenta son: edad del paciente ( $>40$ años), aumento del derrame articular y del edema circundante, así como mayor índice de masa corporal $\left(\geq 24 \mathrm{Kg} / \mathrm{m}^{2}\right)^{6}$

\section{Osteonecrosis de rodilla}

La ON de rodilla afecta a los cóndilos femorales y platillo tibial, denominándose enfermedad de Ahlback cuando se presenta de forma espontánea debido a osteoporosis e insuficiencia subcondral. ${ }^{11}$ Se presenta alrededor de los 60 años, con frecuencia en el sexo femenino en una relación 3 a 1. El cóndilo femoral interno es el sitio más frecuente afectado debido a ser un área de carga, siendo generalmente unilateral.

Está asociada al consumo de corticoides, suele ser bilateral y en pacientes más jóvenes. ${ }^{5}$ La afectación de las mesetas tibiales es poco frecuente.

Los primeros estadios de la lesión se caracterizan por una fractura subcondral sin asociación de hallazgos osteonecróticos, reconocida en RM por una imagen lineal de baja señal ponderada en T1, subcortical, y edema periférico extenso mejor evidenciado en secuencias ponderadas en T2. Al avanzar su estadio, estas lesiones osteonecróticas muestran cambios distales por una cicatrización deficiente, lo que genera reacción y formación de cartílago con tejido fibroso indicativo de retraso o falta de unión. ${ }^{11}$

En RM en secuencia ponderada en T1, la intensidad de señal de la grasa de la médula ósea del cóndilo femoral afectado es reemplazada por un área con baja señal, asociada a una periferia de aún más baja señal (-Figs. 4 y 5). ${ }^{8}$ En la secuencia ponderada en T2 se visualiza lesión central hipointensa con área de señal alta periférica en relación al patrón de edema de la médula ósea (-Fig. 6). ${ }^{11}$

Tiene un buen pronóstico cuando el segmento que se afecta es pequeño o el tratamiento es adecuado (descarga completa de la pierna afectada asociado a analgésicos). En caso contrario, evoluciona a una artrosis grave de rodilla con dolor mecánico invalidante. El hallazgo que más influye en la evolución, es el volumen de la zona condílea de carga que se ha afectado, siendo un pronóstico desfavorable al afectarse $>50 \%$ del tamaño con tendencia al colapso óseo y artrosis secundaria. $^{5,11}$

\section{Osteonecrosis vertebral}

La ON vertebral es una patología poco frecuente. Se postula que la fisiopatología es la consecuencia de la afección del segmento anterior del cuerpo vertebral, por mecanismos
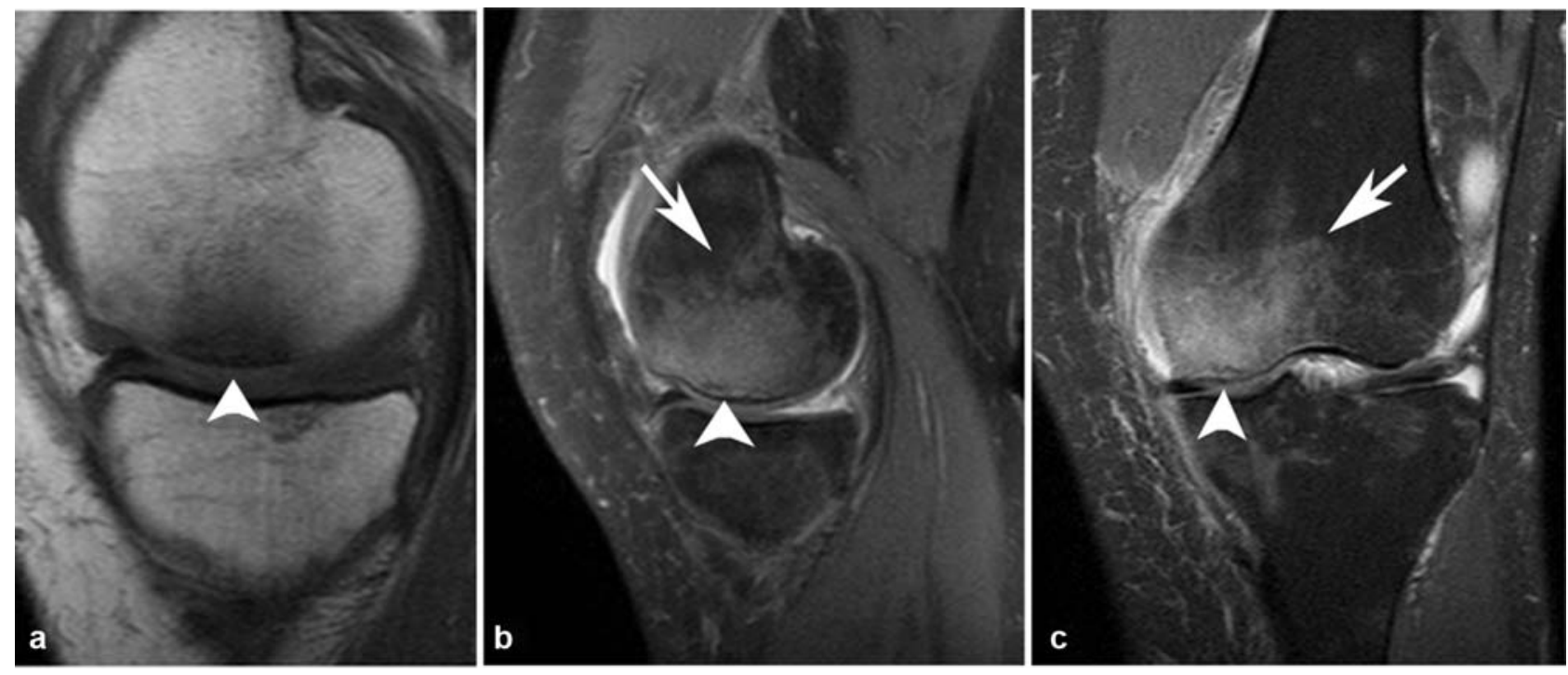

Fig. 4 Paciente de sexo femenino de 68 años con ON de cóndilo femoral: lesión osteocondral a nivel del cóndilo femoral interno (cabezas de flecha en a, b y c), asociada a edema difuso condíleo (flechas en b y c). Nótese pequeña fractura medular subcortical asociada en b. 

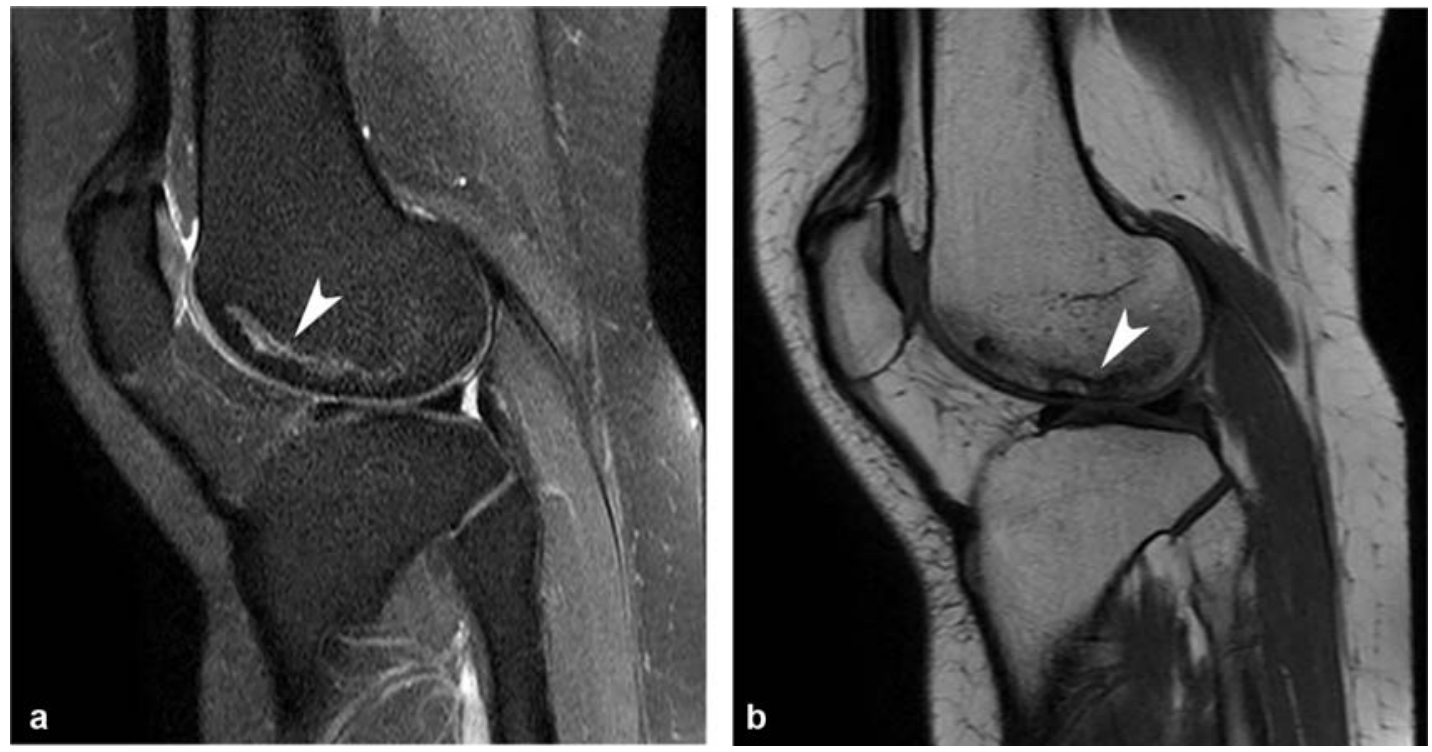

Fig. 5 Paciente de 29 años de sexo femenino con ON de cóndilo femoral. A nivel de hueso subcortical del cóndilo femoral externo se observa imagen serpinginosa, de bordes irregulares de baja señal en todas las secuencias y áreas internas sutiles de alta señal en STIR (a) y señal intermedia/baja ponderada en T1 (b).
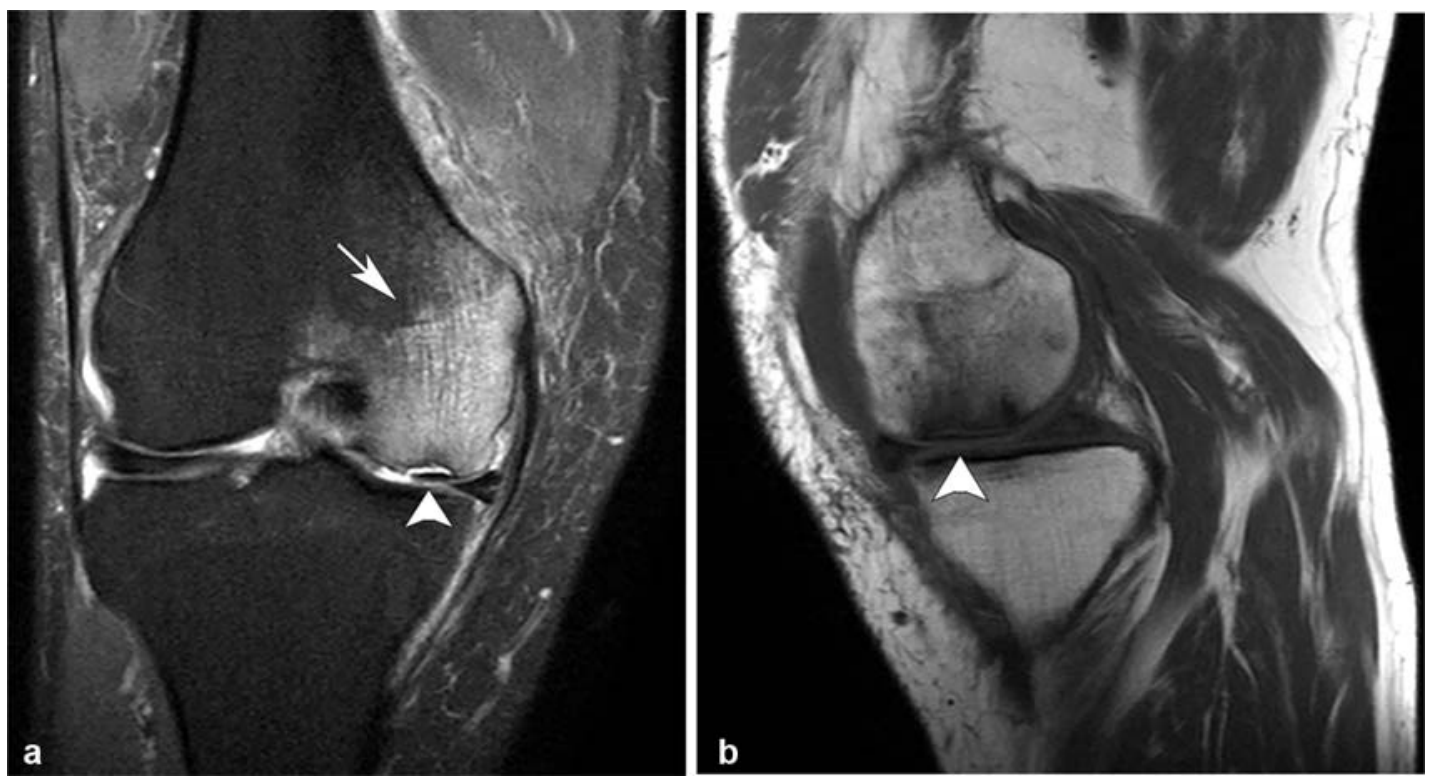

Fig. 6 Paciente de sexo masculino de 76 años con ON de cóndilo femoral: lesión osteocondral disecante se observa a nivel del cóndilo femoral interno (cabezas de flecha en a y b), asociado a marcado edema difuso en el cóndilo (flecha en a). Los hallazgos son sugestivos de patología osteocondral crónica y patología avascular asociada, observándose además signos de edema de partes blandas adyacentes.

traumáticos o no traumáticos. ${ }^{12}$ En el primer caso, se lo llama enfermedad de Kummel y representa un colapso vertebral tardío después de un traumatismo, el cual inicialmente es asintomático acompañado de una radiografías (RX) poco notable que gradualmente se vuelve sintomática y resulta en colapso del cuerpo vertebral. ${ }^{13}$ El segundo mecanismo implica fracturas microtrabeculares repetidas en un cuerpo vertebral que se debilita, y se encuentra asociado al abuso de alcohol, infecciones, glucocorticoides, dislipidemia, enfermedad de Gaucher, inmunodeficiencias, entre otras causas. ${ }^{12}$

Los hallazgos por imágenes de la ON vertebral se pueden acompañar de una colección de aire intravertebral, observándose el signo de la hendidura en descripción a un área radiolúcida semilunar o lineal en las RX o en tomografía computada (TC). Generalmente se encuentra en el área central o adyacente al platillo terminal. ${ }^{14}$

En RM, además de los hallazgos característicos de la ON per se (-Fig. 7), se puede evidenciar una intensidad de señal baja en todas las secuencias y aparece como un vacío de señal en las imágenes de eco de gradiente, debido al efecto de susceptibilidad magnética del aire. También se puede observar una colección líquida en el cuerpo vertebral, que se visualiza como un área circunscripta hipointensa ponderada en $\mathrm{T} 1$ e hiperintensa ponderada en $\mathrm{T} 2 .{ }^{15}$ 

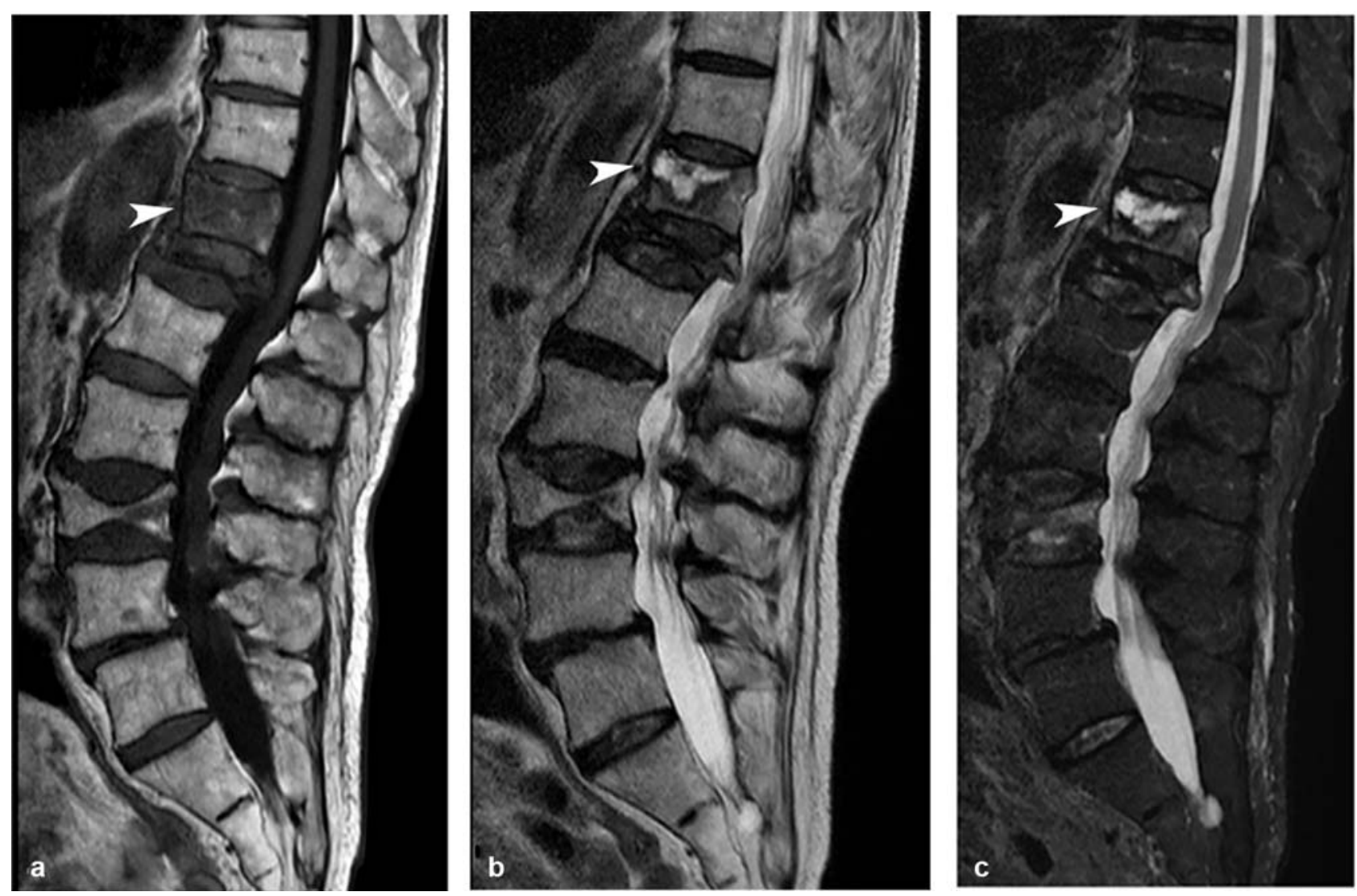

Fig. 7 Paciente de sexo masculino de 97 años de edad con ON de vértebra. A nivel del platillo terminal superior del cuerpo vertebral D11 se observa imagen de señal hipointensa ponderada en T1 (a) e hiperintensa en T2 y STIR (b y c).

\section{Osteonecrosis astrágalo}

El astrágalo es el segundo hueso más grande del tarso y presenta una estructura que permite distribuir el peso corporal. La ausencia de inserciones musculares y escasas ligamentosas en este hueso hace que la vascularización extraósea sea menor que en otros huesos. Además, el 60\% de su superficie presenta cartílago articular, con ausencia a nivel del cuello y parte posterior del cuerpo. ${ }^{16}$ Dentro del hueso, los territorios vasculares son autónomos, la cabeza y el cuello están bien vascularizados por ramas que penetran por la parte superior o inferior del cuello. Por el contrario, el cuerpo presenta una vascularización bastante pobre. ${ }^{17,18}$

La ON del astrágalo guarda una estrecha relación con los traumatismos; la necrosis atraumática solo representa un $10 \%$ de los casos. ${ }^{6,16}$ Existen dos lesiones traumáticas que potencialmente pueden desencadenar la aparición de la ON: fracturas del cuello del astrágalo y dislocación del astrágalo. ${ }^{17}$

Aunque no existe un sistema de clasificación específica, la ON del astrágalo exhibe un patrón característico de la enfermedad. Por lo general, aparece como un área de esclerosis en la cúpula del astrágalo que puede extenderse en el cuerpo talar, con posible colapso de la superficie articular y, en casos graves, la fragmentación de la cúpula del astrágalo y el cuerpo.

La RM es la técnica más sensible, especialmente en las primeras etapas, siendo de mayor ayuda diagnóstica cuando hay una alta sospecha clínica de NOA y los hallazgos radiográficos son normales (-Fig. 8). ${ }^{6,16}$

\section{Osteonecrosis cabeza humeral}

La ON de la cabeza humeral conocida como enfermedad de Hass es la segunda en frecuencia, se desarrolla en la región subcondral, puede provocar colapso del hueso subcondral necrótico, desarrollo de una superficie articular irregular y posterior degeneración de la articulación.

Puede tener varias etiologías: idiopática, secundaria a causas médicas (por fijación quirúrgica o artroscopia), farmacológica o secundaria a un trauma, siendo ésta última la más frecuente. Las fracturas de la cabeza humeral con tres fragmentos pueden desarrollar ON en 3 a $14 \%$ de incidencia, mientras que aquellas con cuatro fragmentos, entre 13 y $34 \%{ }^{19}$

Existe una escala para determinar el grado de severidad de la necrosis mediante hallazgos imagenológicos por RM con el fin de identificar y guiar el tratamiento adecuado, siendo esta la clasificación de Cruess Modificado ( - Tabla 4 ) a partir de la clasificación Ficat y Arlet (-Figs. 9 y 10). ${ }^{20}$

Hertel describe criterios radiográficos como predictores de isquemia para establecer el compromiso vascular de la cabeza humeral: extensión metafisaria de la cabeza humeral de $<8 \mathrm{~mm}$ y la disrupción del eje medial $>2 \mathrm{~mm}$. Estos hallazgos, en asociación a una fractura del cuello 

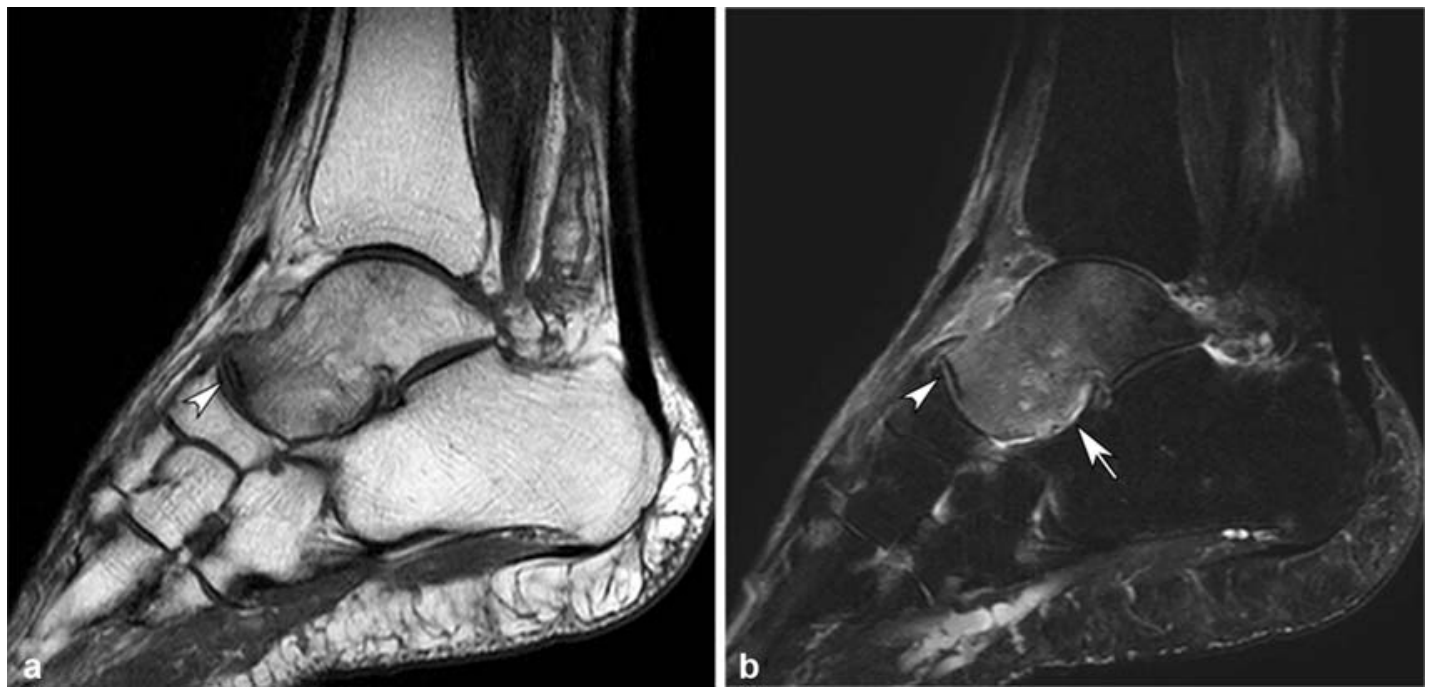

Fig. 8 Paciente de sexo femenino de 68 años de edad con ON de astrágalo. Se evidencia trazo de fractura trabecular subcortical de la cabeza, de baja señal en todas las secuencias (puntas de flecha a y b) relacionado a edema difuso que compromete casi la totalidad del hueso astragalino (flecha en b), preponderando a nivel de cuello y cabeza.

Tabla 4 Sistema de estadificación de Cruess para ON humeral

\begin{tabular}{|l|l|l|l|}
\hline ETAPA & RADIOGRAFÍA & RESONANCIA MAGNÉTICA & CLíNICO \\
\hline I & Normal & Bandas de baja señal & Normal \\
\hline II & Esclerosis moteada & Pérdida uniforme señal & Normal \\
\hline III & Signo de la media luna & Signo de la media luna & Dolor con actividad \\
\hline IV & Colapso extenso & Efusión & Dolor con actividad \\
\hline V & Cambios degenerativos en la glena & Colapso extenso, cambios glenoideos & Dolor en reposo \\
\hline
\end{tabular}
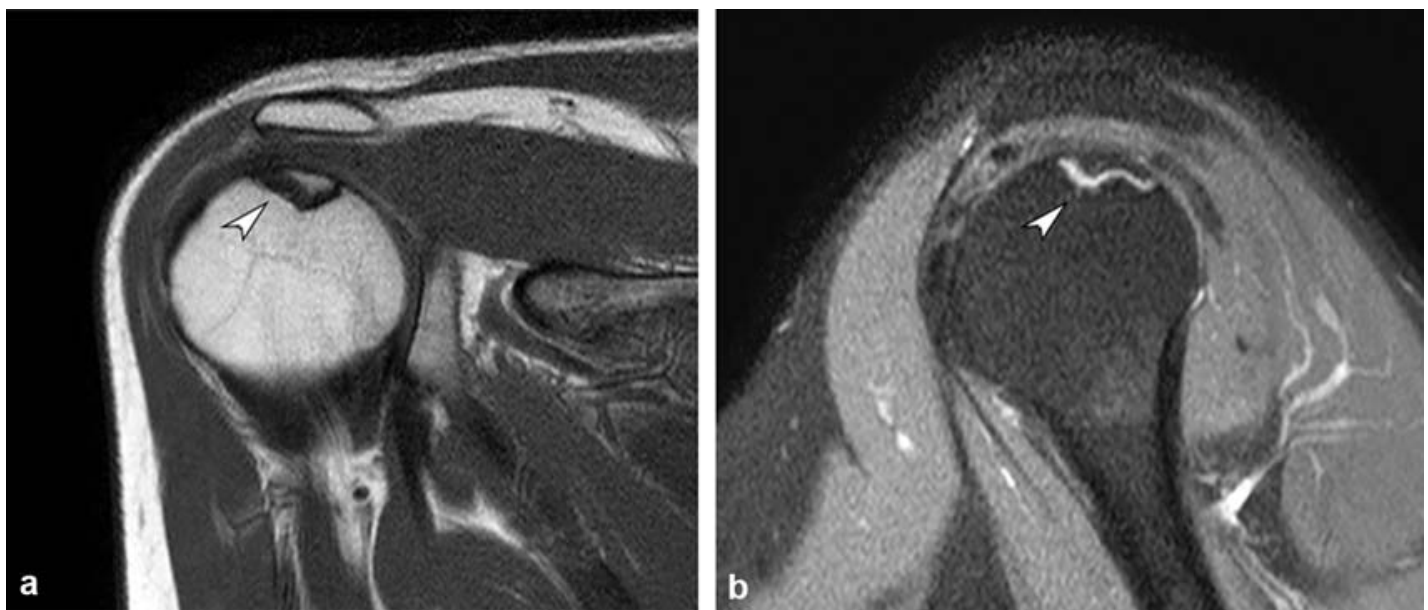

Fig. 9 Paciente de sexo masculino de 42 años de edad con ON de cabeza humeral en estadio III según la clasificación de Cruess. Se observa pequeña imagen subcortical, de bordes geográficos que presenta baja señal ponderada en T1 (a) y alta señal periférica en STIR (b) y señal similar a la grasa a nivel central.

anatómico, presentaron un valor positivo predictivo de $97 \%$ para el desarrollo de isquemia. ${ }^{19}$

El objetivo del tratamiento es preservar la función de la articulación, detener la progresión de la enfermedad y disminuir los síntomas. Los estadios iniciales se manejan con tratamiento conservador: detener factores de riesgo y etiología, fisioterapia, analgesia con cambio en la actividad, y en ocasiones la administración de corticoides intra-articular en pacientes sin factores de riesgo como los inmunodeprimidos. En estadios III y en aquellos pacientes con estadio II que progresan con la enfermedad se realiza la resección focal, injerto óseo vascularizado con el objetivo de descomprimir, algunos no logrando controlar el desarrollo de la enfermedad. El tratamiento más confiable y duradero es el reemplazo de hombro parcial o completo, indicado en pacientes con dolor significativo y disfunción articular con 

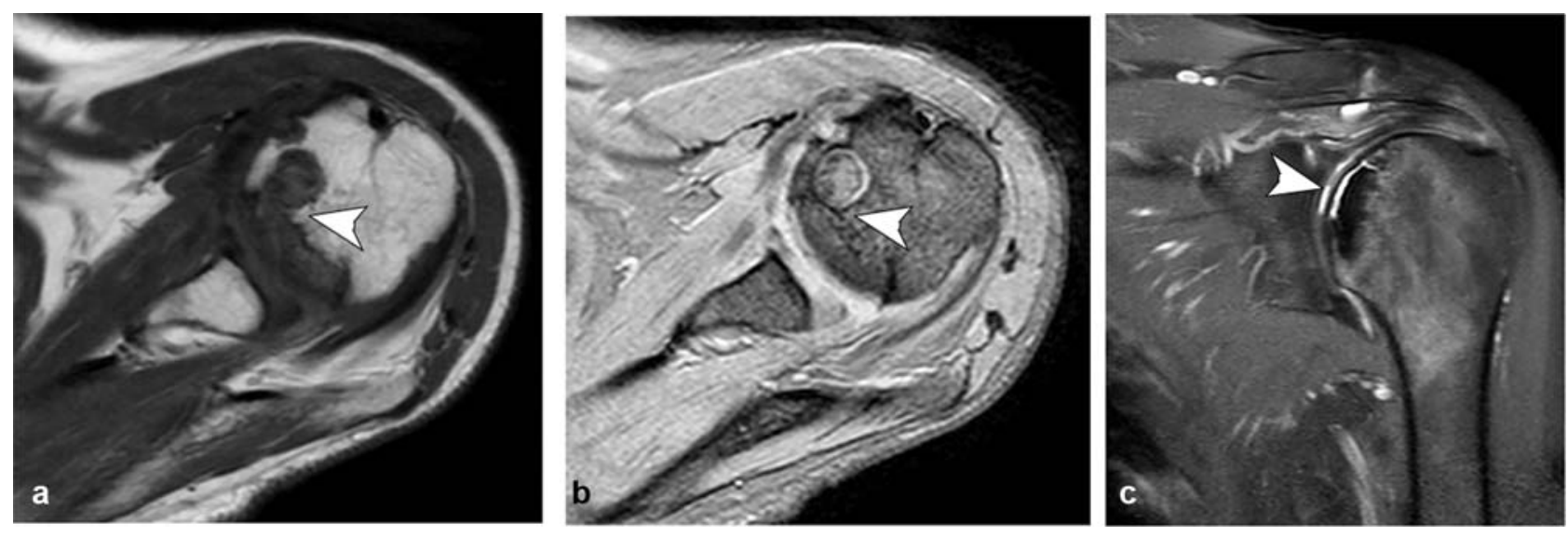

Fig. 10 Paciente de sexo femenino de 60 años de edad con ON de cabeza humeral en estadio IV según la clasificación de Cruess. Se evidencia alteración de la carilla articular del húmero con marcada hipointensidad de señal en la secuencias que ponderan T1 y DP STIR (cabezas de flecha en a y b), asociada a signos de colapso cortical parcial (cabeza de flecha en c).

factores de mal pronóstico, como ocurre en los estadios avanzados. Como en los otros tipos de ON, la artroplastia en pacientes jóvenes sigue siendo controversial. ${ }^{20}$

\section{Osteonecrosis semilunar}

La enfermedad de Kienböck es una afección caracterizada por necrosis avascular del hueso semilunar. Presenta un mecanismo patofisiológico multifactorial, con factores anatómicos que predisponen al desarrollo de la enfermedad, como la varianza cubital negativa y la morfología rectangular o cuboidea del semilunar. ${ }^{21,22}$

Entre los mecanismos para el desarrollo de la ON del semilunar se encuentra la lesión de las arterias dorsales y volares, ya sea por afectación de las estructuras capsuloligamentarias o por fracturas/luxaciones del hueso semilunar. También se puede presentar por lesión neurovascular de las terminales nerviosas carpianas, provocando una reacción vasomotora con una vasodilatación (estasis vascular/descalcificación ósea) vasoconstricción (desencadena un infarto óseo). ${ }^{22}$

Las fracturas del semilunar por compresión secundarias a micro-traumatismos repetidos, que comprometen las entradas vasculares, o secundarias a una varianza cubital negativa, provocan una alteración en el reparto de las presiones en la articulación radio-carpiana, sometiendo a una mayor presión de la mitad cubital de la carilla articular radiosemilunar. $^{22}$

La enfermedad de Kienböck se puede evaluar morfológica y funcionalmente, siendo importante para estimar la progresión de la enfermedad y elegir el tratamiento más adecuado. La evaluación morfológica se realiza con la clasificación de Lichtman ( - Tabla 5), de acuerdo a los hallazgos por RX, TC y RM (-Figs. 11 y 12)..$^{22,23}$ Es altamente confiable y reproducible y tiene mayor relevancia clínica porque ayuda a determinar el tratamiento más adecuado.

El tratamiento se basa en los estadios de la clasificación de Lichtman. El estadio I se enfoca en el tratamiento de descarga con inmovilización y anti-inflamatorios, mientras que en los estadios II y IIla se realizan procedimientos de descarga mecánica, descompresión y revascularización (injertos óseos), en estadios IIIb y IIIc se recomienda la escisión o reconstrucción del semilunar. Finalmente, los procedimientos de rescate como la carpectomía, fusión del hueso carpiano y la artroplastia total de la muñeca se destinan a pacientes en estadio IV. $^{23} \mathrm{~A}$ pesar que se ofrecen muchos procedimientos quirúrgicos, por el

Tabla 5 Clasificación de Lichtman para la evaluación de ON de Kienböck

\begin{tabular}{|c|c|c|}
\hline ESTADIO & RX y TC & RM \\
\hline I & Morfología y densidad normal & Morfología normal e hiperintensidad ponderada en T2 \\
\hline II & Morfología normal y esclerosis en médula ósea & $\begin{array}{l}\text { Morfología preservada } \\
\text { Intensidad baja ponderada en T1, T2 y en DP; } \\
\text { puede coexistir con quistes }\end{array}$ \\
\hline IIIA & $\begin{array}{l}\text { Colapso en hueso semilunar } \\
\text { Ángulo radiocarpiano }<60^{\circ}\end{array}$ & $\begin{array}{l}\text { Colapso del hueso semilunar } \\
\text { Intensidad baja ponderada en T1- variable en T2 }\end{array}$ \\
\hline IIIB & $\begin{array}{l}\text { Colapso en hueso semilunar } \\
\text { Ángulo radiocarpiano }>60^{\circ}\end{array}$ & $\begin{array}{l}\text { Colapso del hueso semilunar } \\
\text { Intensidad baja ponderada en T1- variable en T2 }\end{array}$ \\
\hline IIIC & Colapso en hueso semilunar, crónica & $\begin{array}{l}\text { Colapso del hueso semilunar } \\
\text { Intensidad baja ponderada en T1- variable en T2 }\end{array}$ \\
\hline IV & Artritis degenerativa de la articulación radiocarpiana & Intensidad baja ponderada en T1- variable en T2 \\
\hline
\end{tabular}



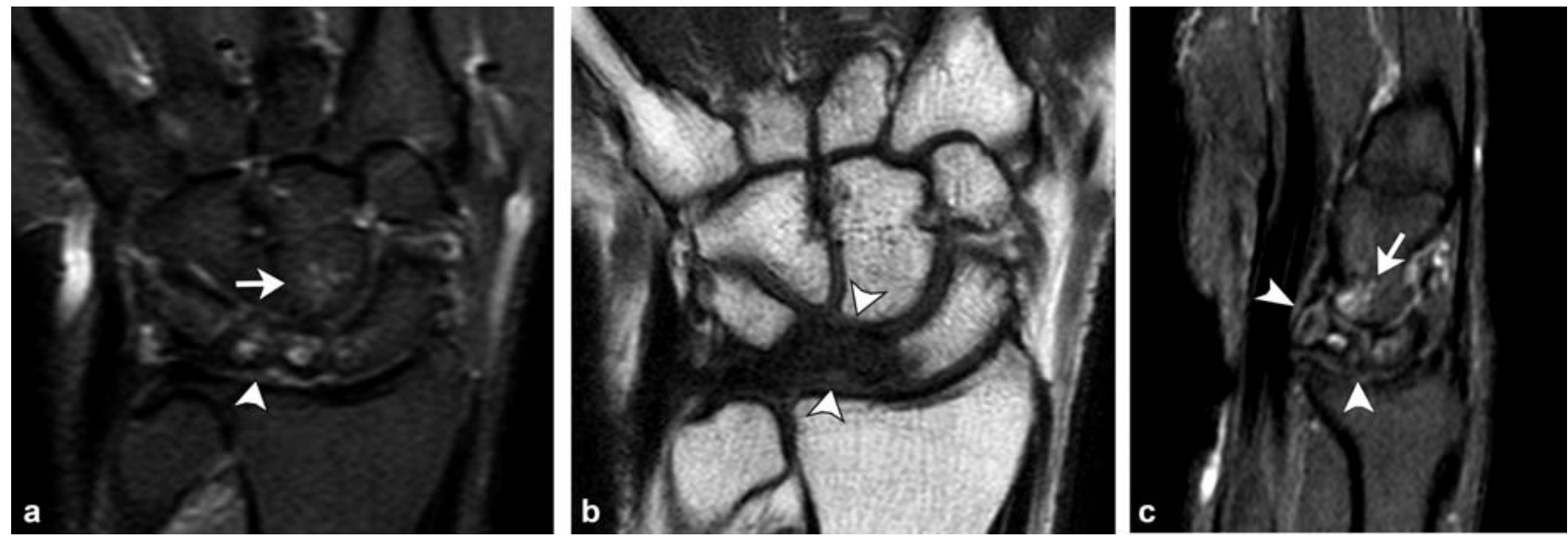

Fig. 11 Paciente de sexo masculino de 35 años de edad con antecedente traumático y ON del semilunar estadio IIIA según la clasificación de Lichtman. Se evidencia colapso del semilunar asociado a áres de edema óseo en STIR (cabezas de flecha a y c), de baja señal ponderada en T1 (cabeza de flecha en b). Obsérvese además foco de edema óseo del hueso grande en secuencias STIR (flecha en a y c).

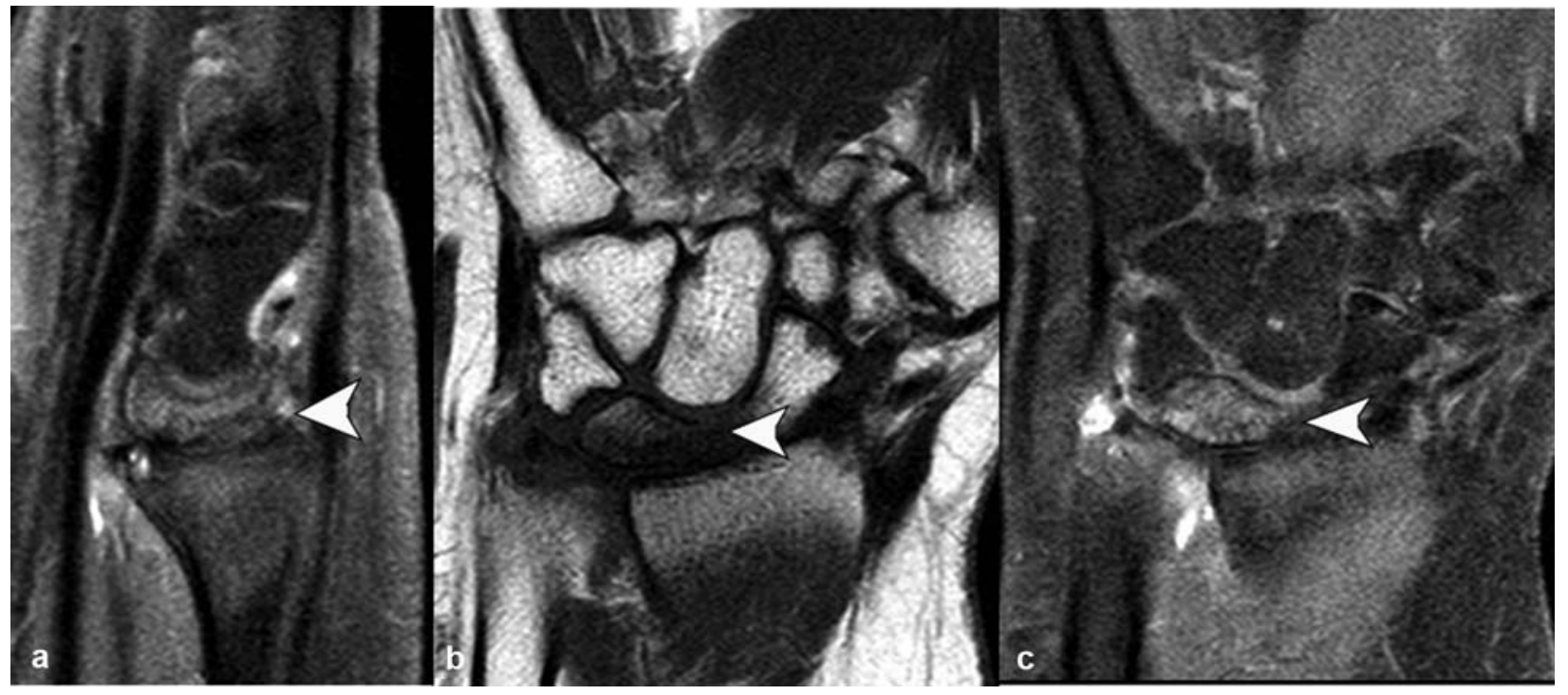

Fig. 12 Paciente de sexo femenino de 66 años de edad con ON del semilunar en estadio IIIB según la clasificación de Lichtman. Se observa disminución de su altura asociada a signos de edema difuso (cabezas de flecha en a y c) y bordes escleróticos (cabeza de flecha en b) a nivel de la superficie articular radial.

momento no hay un tratamiento definitivo para esta enfermedad, al no demostrarse efectividad en la regresión de la enfermedad. Desafortunadamente, la ON de Kienböck es una enfermedad progresiva que termina en la destrucción de la articulación dentro de los tres a cinco años si no se trata a tiempo.

\section{Osteonecrosis escafoidea carpiana y enfermedad de Preiser}

El hueso escafoides tiene grandes segmentos de cartílago hialino que cubre su superficie y, a causa de esto, las superficies externas no pueden ser penetradas por los vasos nutricios. El polo proximal del escafoides está predispuesto a NOA postraumática, debido a la ubicación distal de los principales vasos nutricios y el patrón retrógrado de suministro de sangre intraóseo. ${ }^{24,25}$
Las fracturas de la cintura se asocian a un 30\% de incidencia de NOA, y las fracturas del polo proximal están asociadas a una incidencia cercana al $100 \%$. La necrosis se desarrolla más temprano en pseudoartrosis proximales que en el resto. ${ }^{24}$

La RM nos permite diagnosticar la necrosis en estadios tempranos, así como documentar la vascularización del hueso escafoides antes y después del tratamiento en base a los cambios de señal. La baja intensidad de señal ponderada en $\mathrm{T} 1$ y en $\mathrm{T} 2$ en el polo proximal es muy sugestiva de necrosis avascular.

Se debe tener en cuenta a la enfermedad de Preiser, definida inicialmente como ON idiopática del hueso escafoides del carpo y posteriormente asumida como consecuencia de microtrauma, factores de riesgo vascular o medicamentosa (corticoides, hidroxicloroquina). Se manifiesta en dos tipos: 
Tabla 6 Sistema de estadificación radiológico para ON navicular

\begin{tabular}{|l|l|}
\hline ESTADIO & HALLAZGO RADIOLÓGICO \\
\hline $\mathbf{1}$ & $\begin{array}{l}\text { Se pueden presentar radiografías normales, } \\
\text { pero puede existir una sutil deformidad en varo a } \\
\text { nivel subtalar }\end{array}$ \\
\hline $\mathbf{2}$ & $\begin{array}{l}\text { Subluxación dorsolateral del astrágalo que pro- } \\
\text { duce cavovarus y angulación dorsal de la línea } \\
\text { Meary-Tomeno }\end{array}$ \\
\hline $\mathbf{3}$ & $\begin{array}{l}\text { Compresión o división del navicular que resulta } \\
\text { en un arco longitudinal más bajo y una línea } \\
\text { neutra Meary-Tomeno }\end{array}$ \\
\hline 5 & $\begin{array}{l}\text { Compresión del elemento navicular que con- } \\
\text { duce a la equinización de la pata trasera y la } \\
\text { pérdida del arco longitudinal y la angulación } \\
\text { plantar de la línea Meary-Tomeno }\end{array}$ \\
\hline $\begin{array}{l}\text { Neoarticulación talocuneiforme y extrusión de } \\
\text { un navicular fragmentado también conocido } \\
\text { como listhesis navicularis }\end{array}$ \\
\hline
\end{tabular}

1. Afecta todo el hueso;

2. Afecta de forma parcial o de forma segmentaria al hueso, presenta mejor resolución que el tipo $1 .^{26}$

\section{Osteonecrosis navicular}

La ON navicular, también conocida como síndrome de Müller Weiss, es secundaria a una fuerza de compresión sobre el escafoides tarsal o por un defecto congénito. Se presenta entre los 40 y 60 años de edad, con predominio en mujeres y es frecuentemente bilateral. ${ }^{27}$

Se manifiesta con dolor crónico en la región media y posterior del pie, puede ser bilateral o asimétrica y se asocia a fracturas patológicas. ${ }^{28}$

Los hallazgos radiográficos se presentan en un sistema de estadificación de acuerdo a su progresión (-Tabla 6). ${ }^{27} \mathrm{La}$ RM puede mostrar edema en secuencias STIR o en densidad protónica (DP) con saturación grasa, secuencias sensibles para identificar cambios tempranos debido a la habilidad de detectar cambios de señal medular.

Los hallazgos imagenológicos muestran: una forma adelgazada y fragmentada, esclerosis parcheada similar a ON en otras localizaciones y puede estar asociado a edema de partes blandas.

El tratamiento se realiza en base a los estadios de la enfermedad, optando por medidas conservadoras (antiinflamatorios, aparatos ortopédicos personalizados y restricción de actividad) en los estadios iniciales, o la descompresión central, sin haberse demostrado que sea beneficiosa por sí sola. ${ }^{28}$ El tratamiento quirúrgico se destina a partir de la etapa 3 , ya sea según la gravedad de los síntomas o después del fracaso del tratamiento conservador. Aunque existen múltiples técnicas quirúrgicas, todas presentan dos objetivos comunes: aliviar el dolor mediante la fusión de las articulaciones con cambios degenerativos sintomáticos y restaurar los arcos longitudinales plantar y medial. ${ }^{27}$ La artrodesis talonaviculo-cuneiforme con injerto óseo satisface estos dos objetivos y proporciona los resultados más satisfactorios en relación al pronóstico de la enfermedad. ${ }^{28}$

Es de importancia diferenciarlo de la enfermedad de Köhler, denominada como una ON idiopática que afecta al núcleo de osificación proximal del escafoides tarsiano, por lo que ocurre en población pediátrica, entre los 3 y 7 años de edad, siendo más frecuente en el sexo masculino. ${ }^{29}$ Se caracteriza por un cuadro clínico unilateral, benigno y autolimitado, su etiología es desconocida, pero se sospecha que sea a causa de un incidente vascular. ${ }^{28}$

\section{Otras localizaciones de osteonecrosis}

Existen otras localizaciones de presentación de ON menos frecuentes, como es el caso del compromiso de los otros huesos del tarso, específicamente las cuñas, visualizadas en las -Figuras 13 y 14.
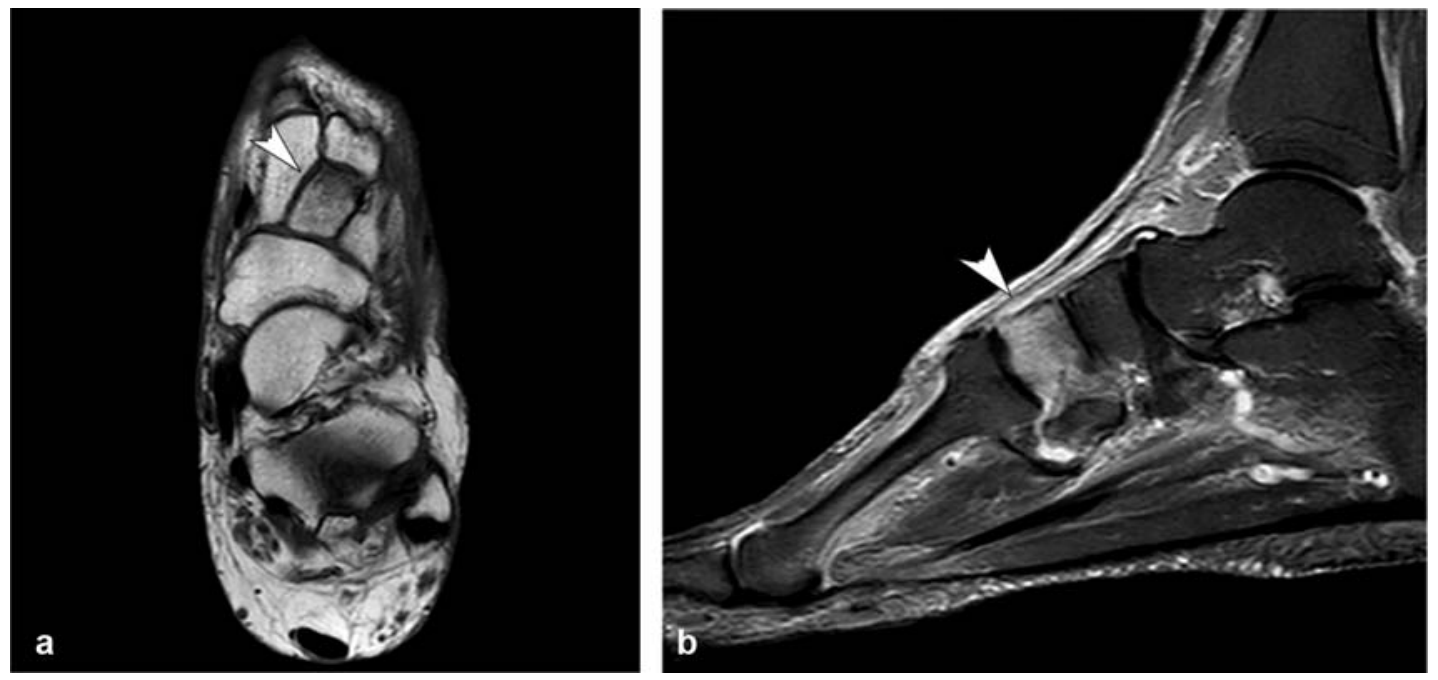

Fig. 13 Paciente de 69 años con ON de segunda cuña. La segunda cuña presenta pequeño trazo subcortical de baja señal ponderada en T1 (cabeza de flecha en a) y edema difuso (cabeza de flecha en b). 

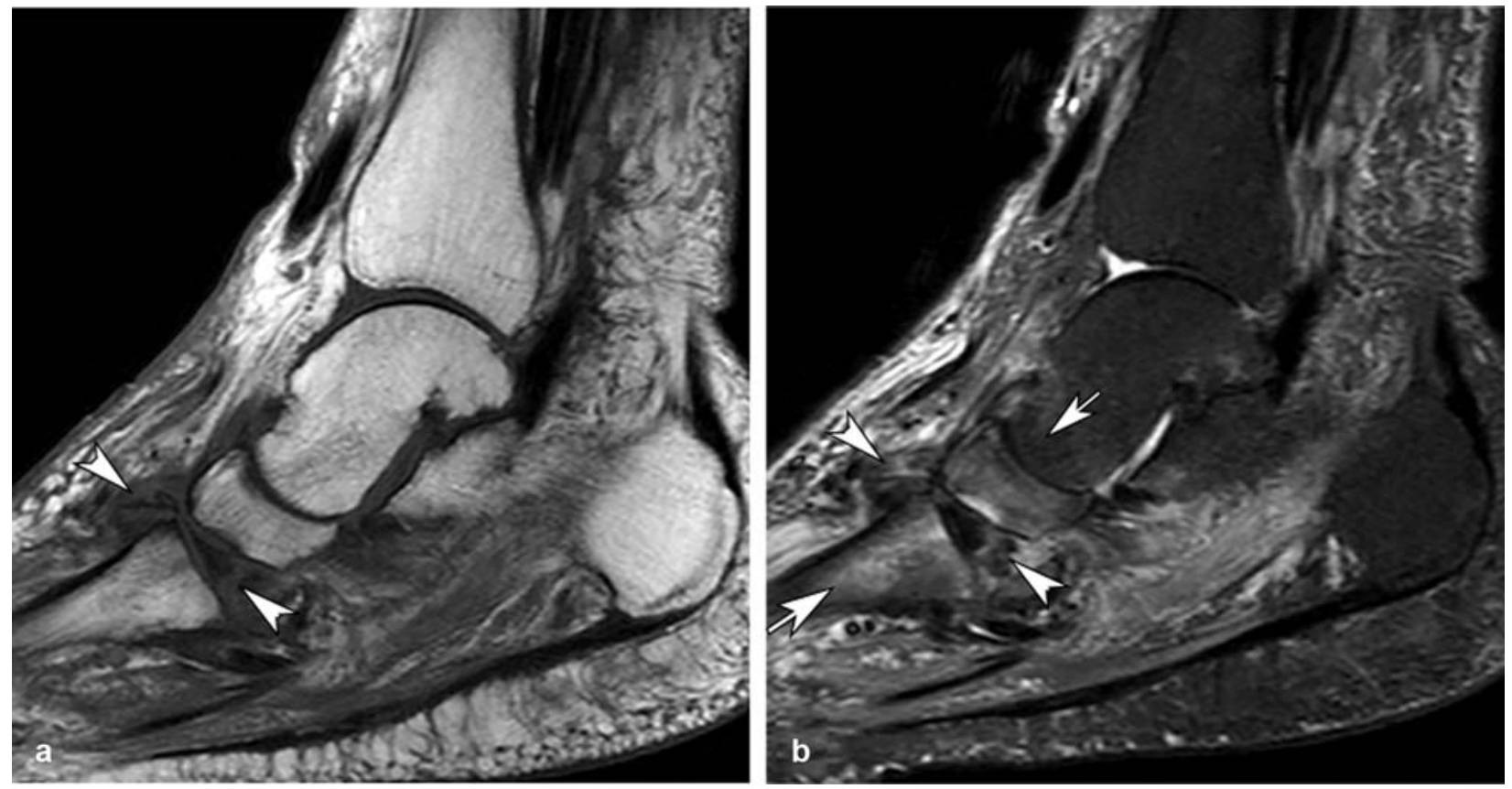

Fig. 14 Paciente de sexo masculino de 61 años de edad con antecedente traumático y ON de tercera cuña. Se observa colapso completo con disminución de la señal de la tercer cuña (puntas de flecha en a y b), en T1 y STIR. Se visualizan además signos de edema a nivel metatarsiano y escafoides (flechas en b).
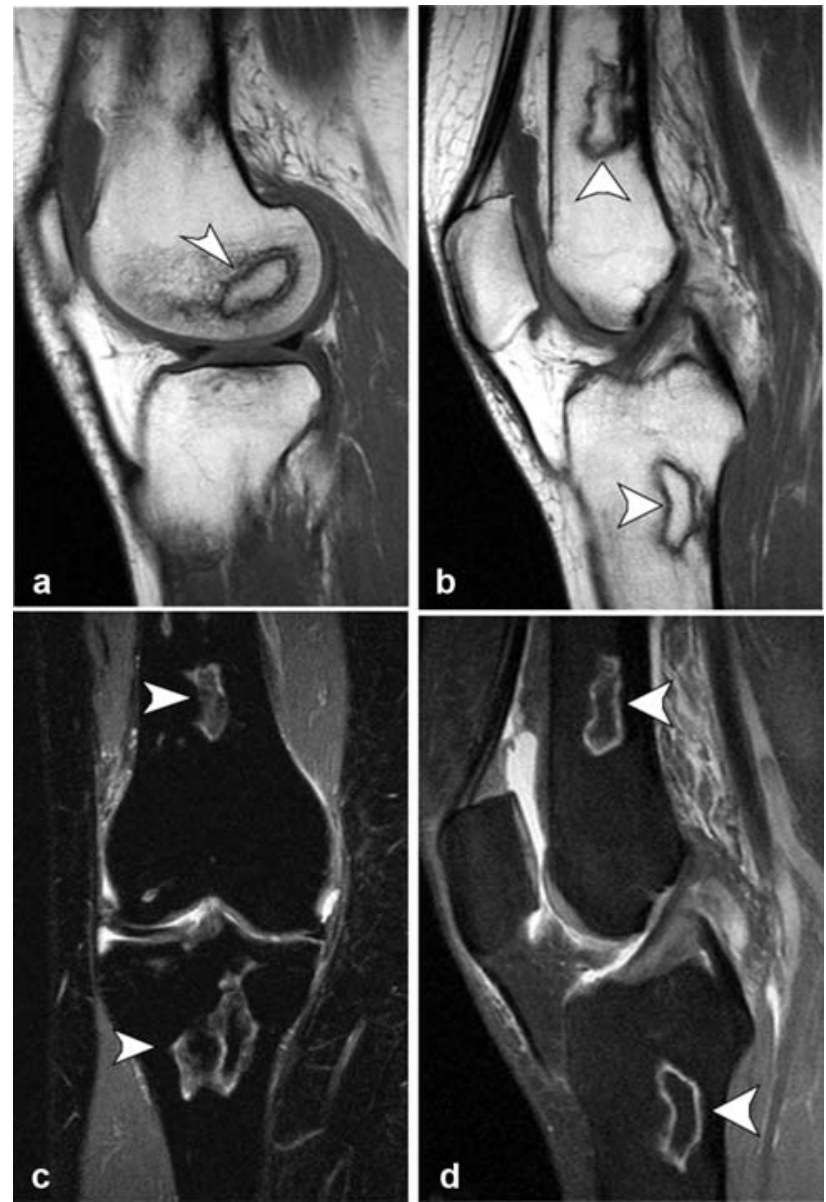

Fig. 15 Paciente de sexo femenino de 39 años de edad con infarto de fémur y tibia: lesiones intramedulares metafiso-diafisarias de señal alta ponderada en T1 (a y b) y baja en STIR ( $c$ y d), con bordes serpiginosos hiperintensos en secuencias de DP y STIR (c y d).

\section{Infartos óseos}

Como ya se ha mencionado, los infartos óseos se definen como la isquemia ósea de la metáfisis y diáfisis de un hueso, con su consiguiente destrucción de la arquitectura ósea, dolor y pérdida de la función.

Fisiopatológicamente hablando, el infarto comienza en el momento en que se interrumpe el suministro sanguíneo en una sección del hueso, lo que da a lugar un núcleo central necrótico rodeado de zona isquémica hiperémica. El déficit del flujo sanguíneo puede ser causado ya sea por compresión vascular, por trauma, por la oclusión de los vasos por burbujas de nitrógeno (enfermedad de Caisson) o por alteraciones de células falciformes. La enfermedad de Gaucher y anemia de células falciforme tienen mayor tendencia al desarrollo de infartos óseos.

En los hallazgos por imagen, los infartos se diferencian del resto de las lesiones de médula ósea por la persistencia de la señal de la médula normal en el centro de la lesión (-Fig. 15) debido a que la médula no se sustituye. ${ }^{30}$

Las características por RM son bastantes distintivas, evidenciándose una lesión de bordes serpiginosos (patrón geográfico) de baja señal ponderada en T1 (-Fig. 16) debido al tejido de granulación y en menor medida a la esclerosis, pudiendo realzar tras la administración de contraste endovenoso (-Fig. 17). En secuencias ponderadas en T2, el infarto agudo se observa como un área inespecífica de alta señal, a veces con signo de doble anillo en relación a anillo interno hiperintenso por el tejido de granulación, visualizado en secuencias de DP con supresión grasa. Los sitios más frecuentes son metáfisis distal femoral, tibia, y húmero. ${ }^{31}$

Se debe mencionar que existen diagnósticos diferenciales en referencia a lo radiológico, incluyendo algunos tumores y 

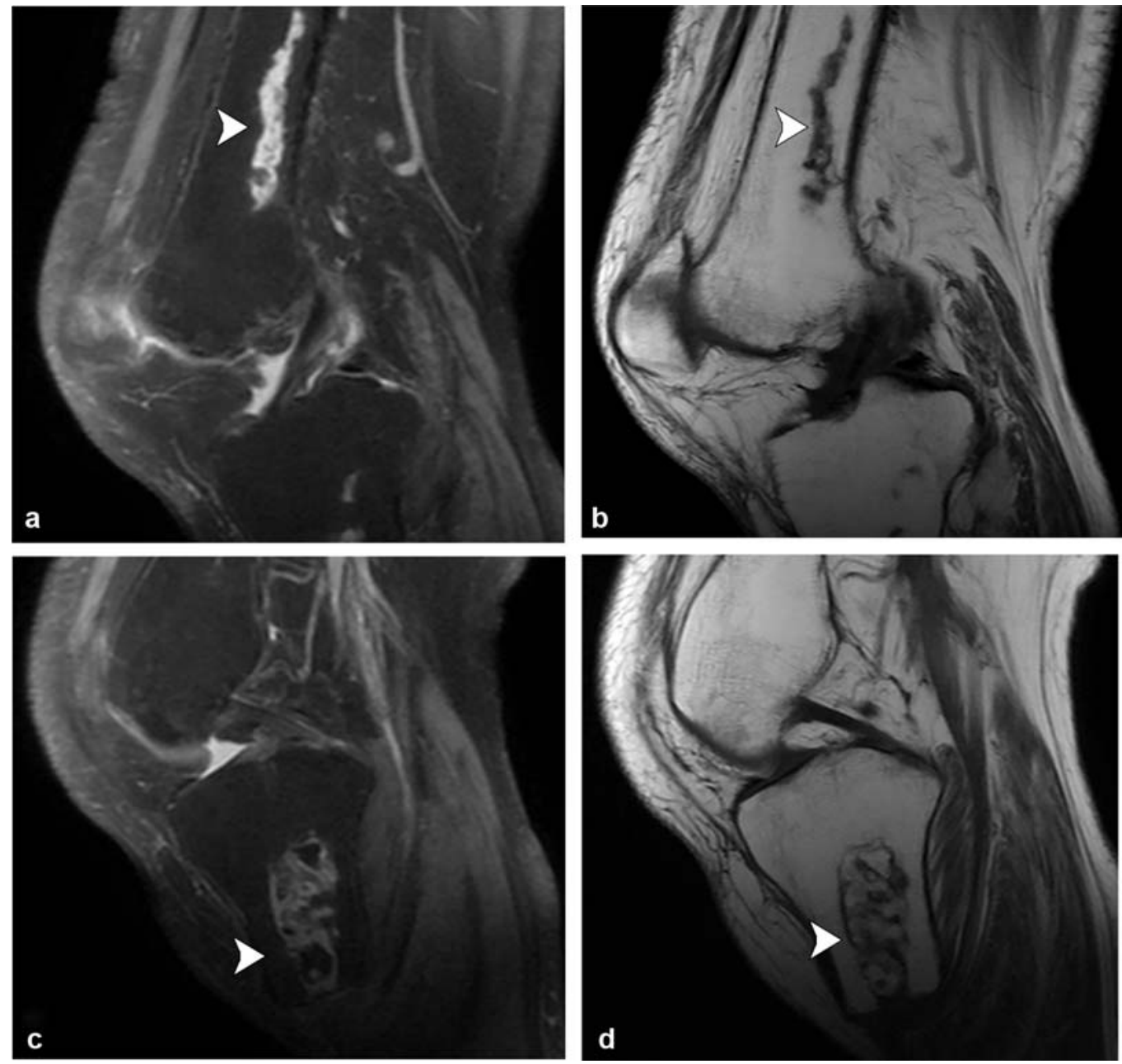

Fig. 16 Paciente de sexo femenino de 51 años de edad con infartos de rodilla. Se observan imágenes que comprometen las metáfisis de los huesos femoral y tibial con áreas periféricas en alta señal en STIR (a y c), bordes geográficos hipointensos ponderados en T1 (b y d) y áreas internas de señal grasa.
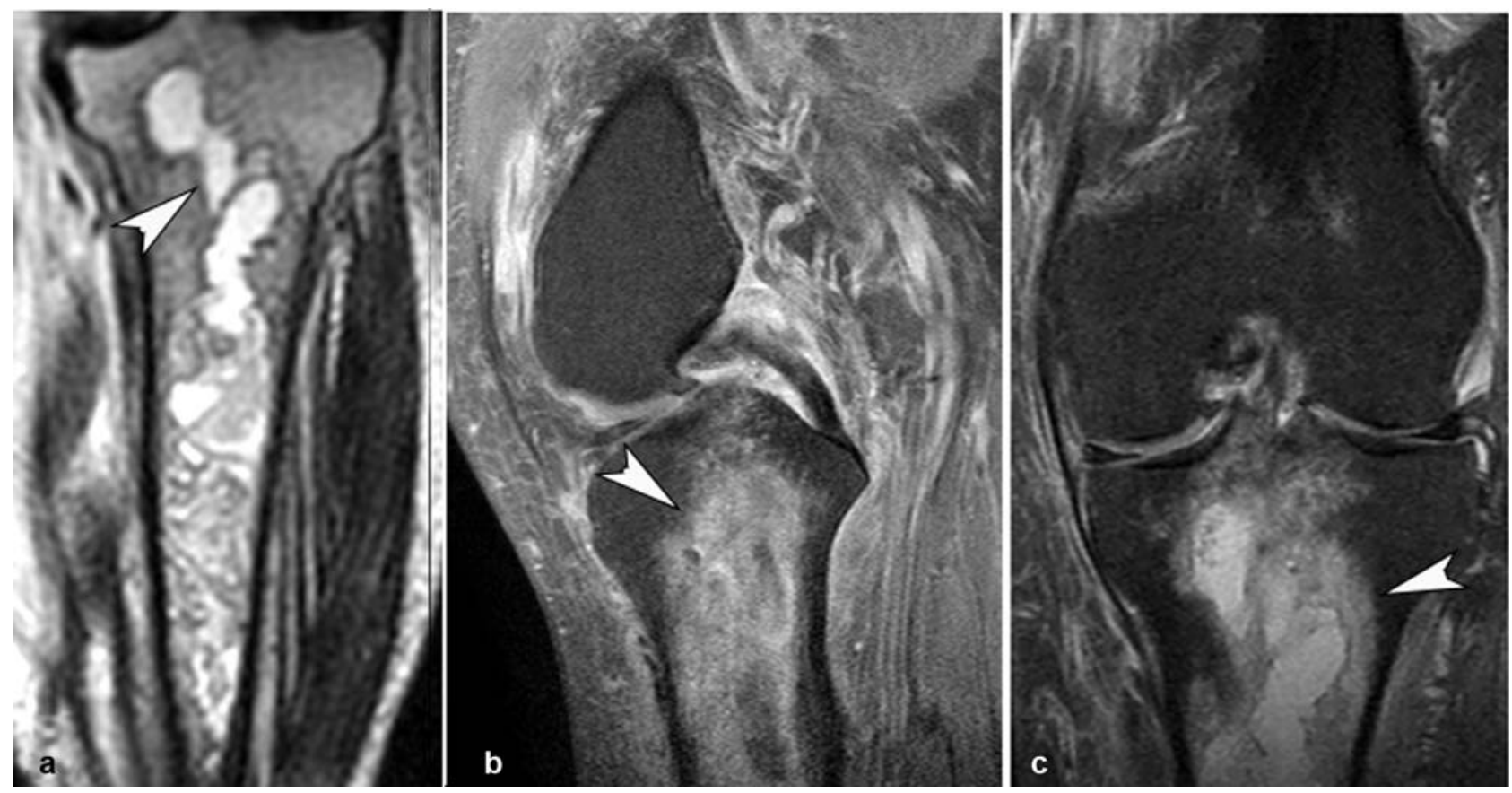

Fig. 17 Paciente de 62 años con infarto tibial comprometiendo la tibia a nivel metafiso-epifisiario. Se observan imágenes con bordes geográficos de alta señal ponderada en T1 (cabeza de flecha en a) y baja señal interna en STIR, mostrando bordes hiperintensos (cabezas de flecha en b y c). 
la osteomielitis, e incluso la posibilidad de malignización en la zona de infarto óseo previo.

Al momento no existe un tratamiento específico, por lo que el enfoque es principalmente paliativo para aliviar el dolor óseo, realizando seguimiento radiológico ante la posibilidad de un diagnóstico diferencial neoplásico. ${ }^{31}$

\section{Conclusión}

El conocimiento de los hallazgos presentes en los procesos avasculares, su clasificación, localización y evolución, permiten el temprano diagnóstico, a fin de evaluar etiología del cuadro y su eventual instauración terapéutica.

\section{Conflictos de intereses}

Los autores del trabajo declaran no tener ningún conflicto de intereses, con excepción de Ricardo Cobeñas, que declara como posible conflicto de interés ser revisor de la RAR.

\section{Bibliografía}

1 Jones L, Mont M. Osteonecrosis (avascular necrosis of bone). UpToDate Web site. https://www.uptodate.com/contents/ osteonecrosis-avascular-necrosis-of-bone. Published 2018. Accessed August 5, 2019

2 Resnick D, Sweet D, Madewell J. Osteonecrosis. En: Resnick D. Huesos y Articulaciones en Imagen. Segunda Edición. Madrid: Editorial Marbán; 2001:941-950

3 Shah KN, Racine J, Jones LC, Aaron RK. Pathophysiology and risk factors for osteonecrosis. Curr Rev Musculoskelet Med. 2015;8 (03):201-209

4 Barrio A. Necrosis avascular y osteocondritis. En: Del Cura JL, Pedraza S, Gayete A. Radiología esencial. Editorial Panamericana; 2010:807-816

5 Tovar J, Noguera J, González J, Navarro Fl. Edema óseo y osteonecrosis. En: Enfermedades reumáticas: Actualización SVR. Segunda edición. Valencia: Sociedad Valenciana de Reumatología. 2013:899-912

6 Murphey MD, Foreman KL, Klassen-Fischer MK, Fox MG, Chung EM, Kransdorf MJ. From the radiologic pathology archives imaging of osteonecrosis: radiologic-pathologic correlation. Radiographics. 2014;34(04):1003-1028

7 Cortés-Motta M, Fernández- Grisales R. Osteonecrosis de los maxilares: fisiopatología, diagnóstico y tratamiento. CES Odontol. 2016;29(02):65-77

8 Chang C, Greenspan A, Beltran J, Gershwin E. Osteonecrosis. En: Kelley and Firestein's Textbook of Rheumatology. Décima edición. Elseiver. 2017:1764-1787

9 Lamb JN, Holton C, O'Connor P, Giannoudis PV. Avascular necrosis of the hip. BMJ. 2019;365:12178

10 Baig SA, Baig MN. Osteonecrosis of the Femoral Head: Etiology, Investigations, and Management. Cureus. 2018;10(08):e3171

11 Sayyid S, Younan Y, Sharma G, Singer A, Morrison W, Zoga A, et al. Subchondral insufficiency fracture of the knee: grading, risk factors, and outcome. Skeletal Radiol. 2019;48(12):1961-1974

12 Pérez E, Elizalde E, Torres J. Vertebral Osteonecrosis. En: Rozim Zorzi A. Osteonecrosis. Intech. 2017:19-42
13 Matzaroglou C, Georgiou C, Panagopoulos A, Assimakopoulos K, Wilke H, Habermann B, et al. Kümmell's Disease: Clarifying the Mechanisms and Patients' Inclusion Criteria. Open Orthop J. 2014; 8(01):288-297

14 He D, Yu W, Chen Z, Li L, Zhu K, Fan S. Pathogenesis of the intravertebral vacuum of Kümmell's disease. Exp Ther Med. 2016; 12(02):879-882

15 Formica M, Zanirato A, Cavagnaro L, Basso M, Divano S, Formica C, et al. What is the Current Evidence on Vertebral Body Osteonecrosis? A Systematic Review of the Literature. Asian Spine J. 2018;12(03):586-599

16 Pearce DH, Mongiardi CN, Fornasier VL, Daniels TR. Avascular necrosis of the talus: a pictorial essay. Radiographics. 2005;25 (02):399-410

17 Caracchini G, Pietragalla M, De Renzis A, Galluzzo M, Carbone M, Zappia M, et al. Talar fractures: radiological and CT evaluation and classification systems. Acta Biomed. 2018;89(1-S):151-165

18 Enge Junior DJ, Fonseca EKUN, Castro ADAE, Baptista E, Santos DDCB, Rosemberg LA. Avascular necrosis: radiological findings and main sites of involvement - pictorial essay. Radiol Bras. 2019; 52(03):187-192

19 Gómez-Mont Landerreche JG, Gil-Orbezo F, Morales-Domínguez H, Flores-Carrillo A, Levy-Holden G, Capuano-Tripp P. Fracturas de húmero proximal: valoración clínica y resultado funcional en pacientes con osteonecrosis de la cabeza humeral. Acta Ortop Mex. 2015;29(02):88-96

20 Panayiotou Charalambous C. Avascular Necrosis of the Humeral Head. En: Panayiotou Charalambous C, ed. The Shoulder Made Easy. Springer. 2019:381-388

21 Kulhawik D, Szałaj T, Grabowska M. Avascular necrosis of the lunate bone (Kienböck's disease) secondary to scapholunate ligament tear as a consequence of trauma - a case study. Pol J Radiol. 2014;79:24-26

22 Arnaiz J, Piedra T, Cerezal L, Ward J, Thompson A, Vidal J, et al. Imaging of Kienböck disease. AJR Am J Roentgenol. 2014;203(01): 131-139

23 Lichtman DM, Pientka WF II, Bain GI. Erratum: Addendum: Kienböck Disease: A New Algorithm for the 21st Century. J Wrist Surg. 2017;6(01):e1-e2

24 Kanthala T, Patel A, Weiss L. Scaphoid Fracture and Avascular Necrosis. En: Kahn S, Xu R, eds. Musculoskeletal Sports and Spine Disorders. Springer. 2017:129-133

25 Tokyay A, Gunal I. Avascular necrosis of the distal pole of the scaphoid. Case Reports Plast Surg Hand Surg. 2015;2(02):40-42

26 Claessen FMAP, Schol I, Kolovich GP, Ring D. Avascular Necrosis of the Scaphoid Preiser Disease. Arch Bone Jt Surg. 2020;8(01): 94-98

27 Samim M, Moukaddam HA, Smitaman E. Imaging of MuellerWeiss Syndrome: A Review of Clinical Presentations and Imaging Spectrum. AJR Am J Roentgenol. 2016;207(02):W8-W18

28 Kani KK, Mulcahy H, Chew FS. Case 228: Mueller-Weiss Disease. Radiology. 2016;279(01):317-321

29 Narváez J, Antonio Narváez J. Osteonecrosis del escafoides tarsiano. Semin Fund Esp Reumatol. 2006;7(03):109-116

30 Helms C. Médula. En: Helms C, Major N, Anderson M, Kaplan P, Dussault R. RM Musculoesquelética. Madrid: Editorial Marbán. 2011:64-69

31 Parashari U, Khanduri S, Bhadury S, Sarkar P. MRI Manifestation and Early Diagnosis of Bone Infarct: A Rare Complication of Steroid Therapy for Pemphigus. Malays Orthop J. 2011;5(02): 50-53 